\section{A CASE OF ERYTHROEDEMA}

\author{
BY
}

\author{
FRANK J. LEES, M.B., CH.B.ABERD.
}

The subject of this report, a female child born in April, 1930, was, until the age of 6 months, an apparently normal healthy baby of contented disposition. Her weight at birth was $8 \frac{1}{2} \mathrm{lb}$. She was not weaned until well on in her illness.

During October the mother noticed that the child gradually went off her feeds, became irritable and fretful, and could not sleep. Marked constipation alternated with occasional passage of loose green stools. Under observation from day to day, the child ran a temperature $\left(99^{\circ}-100^{\circ} \mathrm{F}\right.$.) until about the middle of November, when she became afebrile, and has remained so since. During her illness she never appeared to be in severe pain, nor yet to be actually ill; but she looked miserable and wretched. Extreme restlessness was a marked feature, the child never remaining in the same position for more than a few moments. Photophobia was active during the whole illness, especially marked in the right eye, though neither iritis nor corneal ulcer was present. The eyes were extremely watery and the lids somewhat injected. The lips were cracked, the tongue coated. The pink nose, pink cheeks set in the pale face, watery eyes, photophobia, and aspect of misery, presented a characteristic picture. The child was in poor condition, and appeared to be suffering from a form* of pseudo-paralysis, the neck muscles being so weak that she could not hold up her head. There was also great weakness of the leg muscles. Wasting was marked, especially of the shoulders and inner aspect of the thighs, but never to the point of emaciation. Early in December the child's hands and feet were noticed to be of a bluish-red colour, very cold, swollen, and clammy. This colour did not persist, although the coldness remained. At no time were trophic disturbances of hands and feet observed. Kernig's sign was negative; the heart, lungs, and kidneys were normal ; but the pulse was frequent, never being below 130, and usually 150 . The knee- and ankle-jerks were elicited only with difficulty. There was a copious non-purulent nasal discharge, examination of which showed staphylococci and diphtheria bacilli. Insomnia was very marked. From time to time sweat rashes were observed. Sweating was always excessive. At the beginning of January, 1931, some improvement became evident, the sweating diminished, and there was no recurrence of rashes. The child, however, pacified by nothing the mother could do, remained in a miserable and restless state, and cried incessantly. During her less miserable periods she would scratch her genitals and the lobes of her ears, making the latter bleed. About the middle of January general improvement was noted, the hands and feet became warmer, and the appetite improved:- Bouts of crying still occurred, but did not last so long. In the intervals she was quite comfortable, and if shielded from the light opened her eyes, held her head up better, grasped and handled articles, and played with her toes. Gradually the crying and restlessness subsided, and she slept better. 'The nasal discharge still continued very profuse. Towards the end of that month she opened her left eye well, but the right eye still showed great sensitiveness to light. During February the child gradually gained strength; her muscles increased in tone, and she held her head erect for longer periods of time. She put on weight fairly quickly, the adductor parts of the thighs especially appearing to fill out and become firm. She had then six teeth, and all seemed firmly fixed in their sockets. She still had slight photophobia in the right eye, which soon cleared up. The hands and feet became warm, she lost all signs of misery, and became happy and contented, playing with her toys and taking notice of things going on around her. She now appears to be perfectly well, except for a liability to colds in the head and to bronchial catarrh.

The treatment was purely symptomatic; a mother's patience and care being facile princeps. Bromides and chloral were tried, and appeared to give some small relief. Resorcin was thought to diminish the nasal discharge. Early on in the disease the child was partially weaned, and care was taken to provide her with ample vitamins.

\section{COMmentaRy}

Erythroedema, or pink disease, has been recognized only recently as a clinical entity. Known in Australia for twenty-five years, it was first accurately described by Swift ${ }^{1}$ in 1918, and by Weston in England in 1920 . The most constant symptom is a marked change in the disposition of the child: According to Langmead, 2 intolerable itching is prominent; and he relates that Zahorsky mentions two children who continually pulled their hair out. Langmead also says that the deep reflexes tend at first to be exaggerated, but later to become weakened or lost. $\mathrm{He}$ remarks that a leucocytosis of from 12,000 to 30,000 is the rule in severe cases. Vipond ${ }^{3}$ lays great stress on the pains in the extremities, saying that this suffering produces an abnormal mental condition, characterized by an extremely high degree of irritability and restlessness which has not been observed in any other disease. He also notices a peripheral neuritis in his cases, with diminution or loss of cutaneous sensibility. $\mathrm{He}$ says: "I have proved this condition by putting a needle into an inguinal node without the little one suffering intense pain." According to him, the age of onset is from 8 to 18 months, and the duration of illness from four to six months. $\mathrm{He}$ found in the lymph nodes in every case a small Grampositive diplococcus, from which he made an autogenous vaccine which, he claims, gave good results. Parsons ${ }^{4}$ thinks there may be some food-deficiency factor present, and suggests yeast.

Erythroedema must not be confused with acrodynia, which is an epidemic disease of adults (Paris, 1928, epidemic). The former is a sporadic disease met with typically in children; it is a self-limiting disease, and recovery is complete in from three to six months.

1 Swift: Lancet, 1918, i, 611

$$
\text { References }
$$

${ }^{2}$ Langmead, F.: Medical Annual, 1924, 167

${ }^{3}$ Vipond, A. E.: Brit. Journ. Child. Dis., 1926, xxiii, 127.

4 Parsons: Practitioner, July, 1930, 153.

\section{Memoranda \\ MEDICAL, SURGICAL, OBSTETRICAL}

\section{THE BINOSCOPE}

The binoscope is an apparatus for training binccu'ar vision. The plan of its construction is based upon that which Nature apparently employs for bringing about and maintaining the habitual use of the vision of both eyes simultaneously in this our highest type of sight, triefly as follows :

In an open space we can see the horizon for about half a circle-that is, the combined field of vision with both eyes extends through nearly 180 degrees from side to side. Rather more than one-third of this in the central part, where the vision of each eye overlaps that of the other, is seen with both eyes in binocular vision. In this part each object is seen with both eyes at the same time, yet it is seen as one object, for the two imagesone on each retina-fall upon the corresponding points which exist in both retinae where the vision overlaps The lateral parts of the field of vision are seen with 